TAO, Vol. 16, No. 3, 653-675, August 2005

\title{
Calculating Highly Fluctuated Suspended Sediment Fluxes from Mountainous Rivers in Taiwan
}

\author{
Shuh-Ji Kao ${ }^{1,2, *}$, Tsung-Yu Lee ${ }^{1}$, and John D. Milliman ${ }^{3}$
}

(Manuscript received 1 February 2005, in final form 5 July 2005)

\begin{abstract}
Small drainage basins, highly fractured rock, high relief, and steep gradients make Taiwan watersheds particularly sensitive to episodic events such as typhoons and earthquakes, and to various types of anthropogenic disturbance. Here we analyze the characteristics of a long-term hydrological dataset from Taiwan and re-evaluate methods used to calculate sediment loads for Taiwan's event-driven rivers. We suggest using the rating curve method stratified down to seasonal levels to reflect the rapid changes in the relationship between water discharge and suspended sediment load. A program is developed to determine the optimal time-interval for constructing rating curves, and is used to calculate hourly, daily, yearly, and long-term mean suspended sediment loads. Seasonal rating curves applied to hourly discharges are particularly critical to calculate sediment fluxes and concentrations in response to episodic events, particularly typhoons. The calculated cumulative long-term mean sediment fluxes for the JhouShuei and Bei-Nan Rivers are considerably smaller than those calculated using monthly weighted average (MWA) method (Dadson et al. 2003). The MWA method likely over-estimates the mean load due to more frequent sediment observations during high-flow events.
\end{abstract}

(Key words: Suspended sediment flux estimate, Rating curve, Taiwan)

\section{INTRODUCTION}

In recent years, increasing attention has been paid to rivers draining high-standing Oceania

\footnotetext{
${ }^{1}$ Research Center for Environmental Changes, Academia Sinica, Taipei, Taiwan, ROC

2 Institute of Hydrological Sciences, National Central University, Chung-Li, Taiwan, ROC

3 School of Marine Science, College of William and Mary, Gloucester Pt, VA 23062, USA

* Corresponding author address. Dr. Shuh-Ji Kao, Research Center for Environmental Changes, Academia Sinica, Taipei, Taiwan, ROC; E-mail: sjkao@rcec.sinica.edu.tw
} 
islands, which account for only a few percent of the Earth's surface, but may collectively contribute as much as $40 \%\left(9 \mathrm{Pg} \mathrm{yr}^{-1}\right)$ of the world's fluvial suspended sediment flux to the oceans (Milliman and Syvitski 1992; Milliman et al. 1999). Given its high tectonic activity, frequent typhoons, highly erodable rocks, high relief (mountain elevations locally approaching $4000 \mathrm{~m}$ ), and steep gradient, the island of Taiwan is generally recognized as having particularly high sediment production rates (Li 1976; Milliman and Meade 1983), as evidenced by the fact that 7 of the 10 global rivers with the highest sediment yields are Taiwanese (Milliman and Syvitski 1992)

The Taiwan Water Resources Agency (WRA), Ministry of Economic Affairs, has a rich archive of decades of hydrological data from more than 150 gauging stations across the island. Many stations have more than 35 years of observations, and a few extend back to the 1940s, providing one of the richest data banks in the world. Recently, Dadson et al. (2003) applied monthly weighted average method onto all the WRA's gauging stations, and reported the long-term means of suspended sediment load. Their obtained values, however, are significantly higher (sometimes 3-fold) than those published by the WRA, although based on the same database.

A sufficiently long historical record is essential in studying how mountainous watersheds respond to both the natural setting and various types of human perturbations (e.g., Syvitski et al. 2000; Krishnaswamy et al. 2001; Kao and Liu 2002; Dadson et al. 2003; Farnsworth and Milliman 2003). However, to resolve impacts of natural and anthropogenic forcing (e.g., road construction, reservoir building, and agriculture) on fluvial sediment discharge (Milliman 1991; Kao and Liu 1996, 2000, 2001, 2002; Liu et al. 2000) a better estimator is needed for calculating both annual and long-term sediment mean loads. Since annual sediment load is often determined by infrequent events, the estimator must achieve sufficient predictive capability of these events. This paper aims to review and evaluate methods having been adopted to Taiwan's rivers, discuss the characteristics of WRA's hydrometric dataset, and then develop an optimal estimator to estimate hourly, daily, yearly and therefore long-term mean annual loads for Taiwan's rivers.

\section{THE WRA HYDROMETRIC DATASET}

In this paper we analyze data from downstream gauging stations on the 16 primary rivers in Taiwan (Fig. 1 and Table 1). Recently the spelling of Taiwan river names was changed to reflect local pronunciations. In this paper we use the new spelling, although we also list old names in Table 1. All the downstream stations are above tidal influence, giving a fair estimate of sediment discharge to the sea. Over the years the downstream gauging stations on the Tou Cian (TC), Jhuo-Shuei (JS), Zeng-Wun (ZW) and Gao-Ping (GP) rivers were moved several kilometers landward due to coastal retreat or the construction of new bridges. Because station relocation generally changed drainage basin areas by only a few $\mathrm{km}^{2}$, separated record periods are combined.

The WRA hydrometric dataset includes: (1) discrete data of suspended sediment concentration ( $C_{s}$; e.g., Fig. 2) and corresponding water discharge $(Q),(2)$ records of daily water 


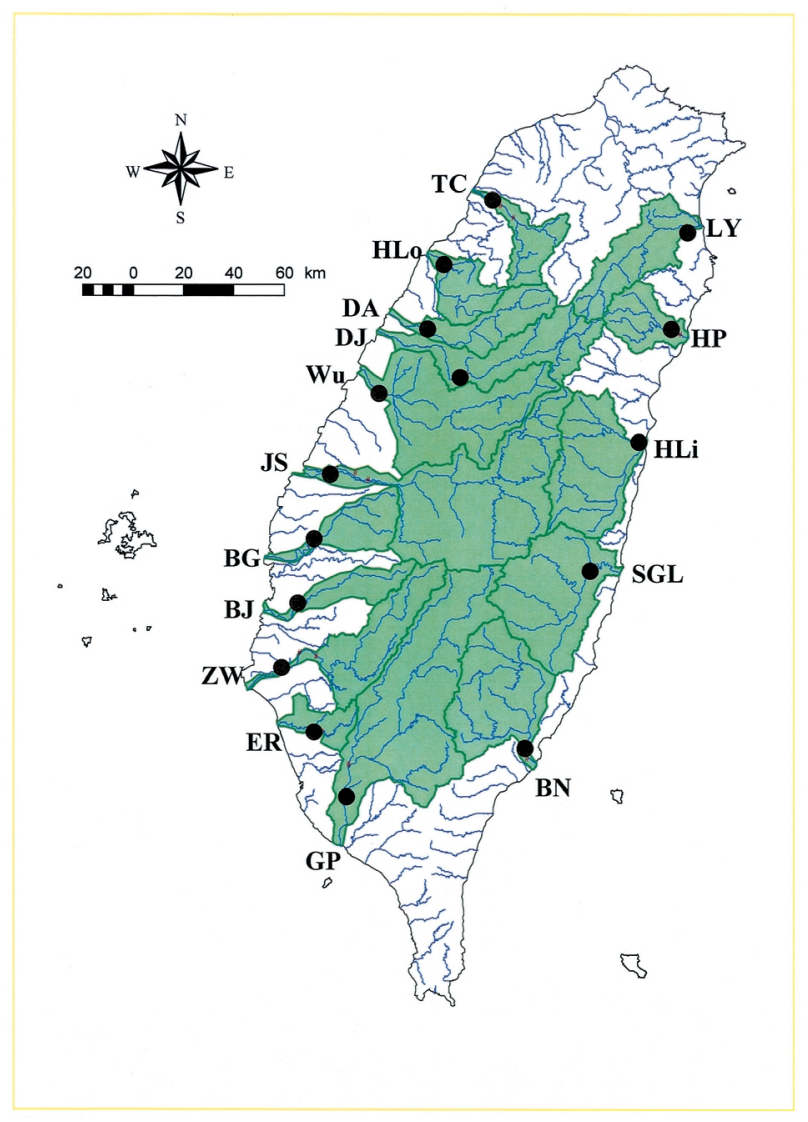

Fig. 1. Location map for 16 river watersheds in Taiwan. Dots represent gauging stations. Full names of rivers are listed in Table 1.

discharge (Fig. 2), and (3) hourly water discharge (based on river stage) during floods. Daily mean water discharge was calculated as the mean of hourly water discharges. The observed suspended load $\left(Q_{s}\right)$ is obtained by multiplying the corresponding water discharge by $C_{s}$. The publication of WRA Hydrological Yearbooks started in 1970. The records prior to 1970 as well as hourly data were not published but are stored in data files at the WRA archive. In this paper, we use entire data records (Table 1).

\subsection{WRA's Sediment Sampling}

Sediment samples at various gauging stations are taken on average $20 \pm 12$ times per year (Table 1). The WRA used the standard USDH-48 depth-integrated suspended sediment sampler recommended by the Federal Interagency Sedimentation Project of the USA (http://fisp. wes.army.mil/). 
Table 1. Basic parameters and sediment records for 16 studied river watersheds.

\begin{tabular}{ccccccc}
\hline River (abbrev.) & Old name* & $\begin{array}{c}\text { Basin area } \\
\left(\mathrm{km}^{2}\right)\end{array}$ & $\begin{array}{c}\text { Water discharge } \\
\left(\mathrm{km}^{3}\right)\end{array}$ & $\begin{array}{c}\text { Runoff depth } \\
(\mathrm{mm} / \mathrm{y})\end{array}$ & $\begin{array}{c}\text { Record } \\
\text { period }\end{array}$ & $\begin{array}{c}\text { Days with sediment } \\
\text { observations }\end{array}$ \\
\hline Tou-Cian (TC) & Touchien & 499 & 0.66 & 1370 & $1951-2002$ & 642 \\
Hou-Long (HLo) & Houlung & 472 & 0.63 & 1328 & $1981-2002$ & 440 \\
Da-An (DA) & Taan & 633 & 0.95 & 1504 & $1966-2002$ & 804 \\
Da-Jia (DJ) & Tachia & 916 & 1.83 & 1999 & $1979-2002$ & 731 \\
Wu (Wu) & Wu & 1981 & 3.61 & 1824 & $1966-2002$ & 1080 \\
Jhuo-Shuei (JS) & Choshui & 2975 & 3.68 & 1234 & $1964-2002$ & 1187 \\
Bei-Gang (BG) & Peikang & 597 & 0.76 & 1278 & $1949-2002$ & 693 \\
Ba-Jhang (BJ) & Pachang & 441 & 0.64 & 1448 & $1960-2002$ & 543 \\
Zeng-Wun (ZW) & Tsengwen & 988 & 1.04 & 919 & $1960-2002$ & 590 \\
Er-Ren (ER) & Erhjen & 140 & 0.29 & 1740 & $1971-2002$ & 552 \\
Gao-Ping (GP) & Kaoping & 3076 & 7.25 & 2389 & $1951-2002$ & 1080 \\
Bei-Nan (BN) & Peinan & 1584 & 3.02 & 1906 & $1948-2002$ & 1731 \\
Siou-Gu-Luan (SGL) & Hsiululuan & 1539 & 3.31 & 2153 & $1969-2002$ & 342 \\
Hua-Lien (HLi) & Hualien & 1506 & 3.13 & 2076 & $1969-2002$ & 347 \\
Ho-Ping (HP) & Hoping & 553 & 1.18 & 2142 & $1975-2002$ & 699 \\
Lan-Yang (LY) & Lanyang & 821 & 1.97 & 2397 & $1949-2002$ & 1484 \\
\hline
\end{tabular}

* The WRA used the new spelling since 2002.

Water discharge and runoff range from 0.3 to $7 \mathrm{~km}^{3} \mathrm{yr}^{-1}$ and $\sim 1000$ to $2400 \mathrm{~mm} \mathrm{yr}^{-1}$, respectively (Table 1). For most parts of Taiwan, 50 to $70 \%$ of the annual total water discharge occurs in the summer. During typhoons discharge can increase by 2 to 3 orders of magnitude within 24 hours, and generally lasts no more than 1 or 2 days before declining sharply (Fig. 2). During typhoon seasons, sediment concentrations increase over 2 orders of magnitude (Fig. 2) concomitant with a 3-order-of-magntidue increase in water discharge. Apparently, typhoon floods play the major role in sediment discharge (e.g., Milliman and Kao 2005).

\section{$2.2 Q_{s}-Q$ Relationship}

After pooling long-term records, positive relationships between $Q_{s}$ and $Q$ appear for all 16 rivers (Fig. 3), corroborating that Taiwan's rivers are mainly transport-dominated (Kao et al. 2005). The 6-8 order-of-magnitude ranges of $Q_{s}$ during flood periods is a consequence of increased erosion and sediment mobilization during storms and increased surface runoff (Milliman and Meade 1983; Milliman and Kao 2005).

The 16 positive trends (Fig. 3), however, exhibit different patterns. The LY and BN Rivers have the most diffusive $Q_{s}-Q$ plots, suggesting that the watershed conditions have changed with time. The HLo, DA, Wu, JS and GP have relatively tight trends. Some trends bend up- 


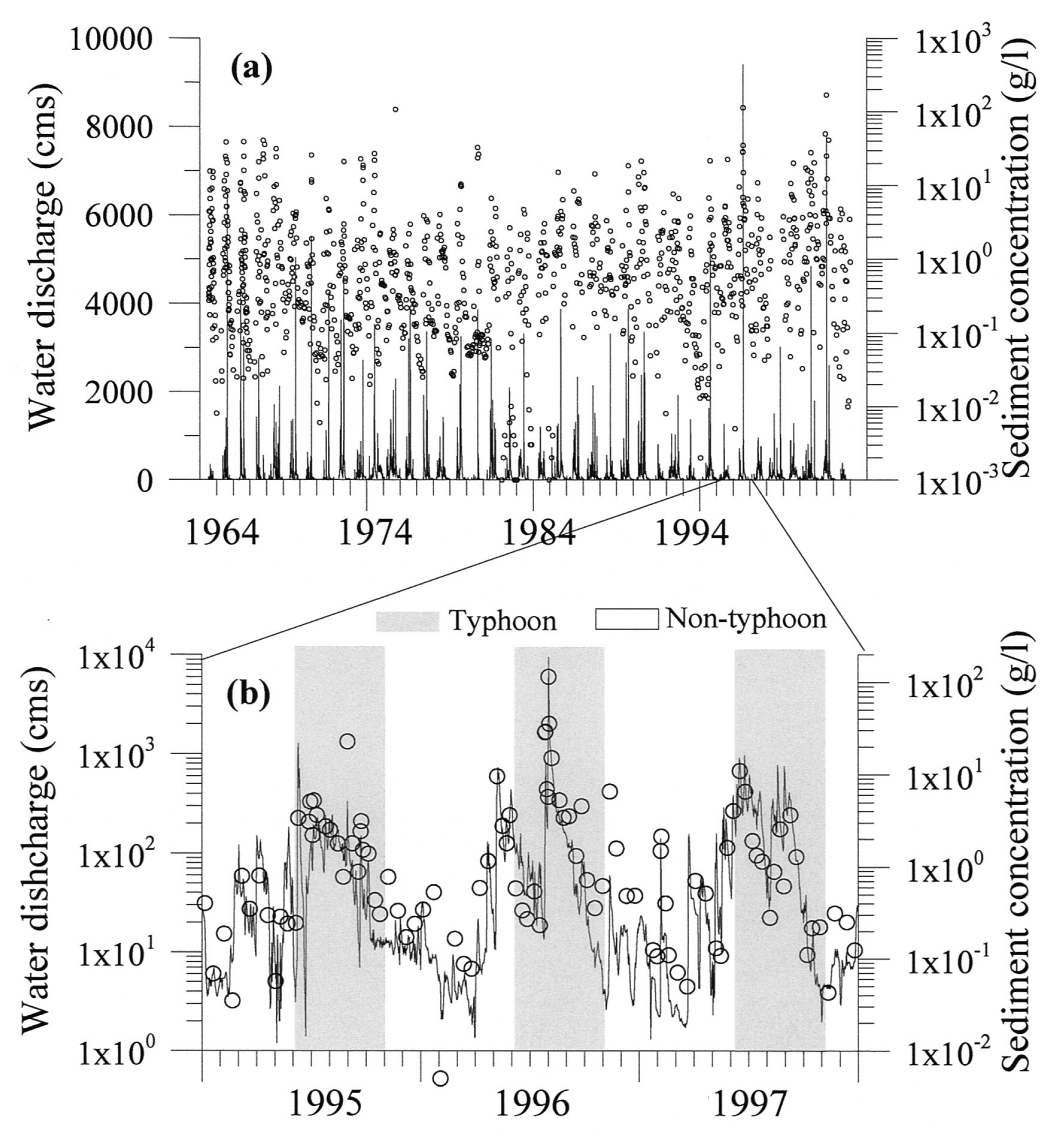

Fig. 2. Water discharge rate and sediment concentration recorded for the JhuoShuei River during the period of 1964 to 2002 (a) and 1995 to 1997 (b). Curves represent water discharge rates and open circles are for sediment observations. Note that the water discharge scale in (b) is logarithmic. Gray area marks the typhoon season from June to October.

ward at high flow rates (e.g., TC, HLo and DJ), and some bend downward (e.g., BJ, ER and HP). These various sediment transport patterns presumably reflect a combination of natural and anthropogenic processes within the watersheds.

Multiple natural and anthropogenic factors interplaying with complex sediment delivery processes, such as erosion, transport, and/or deposition within the basin and river channel, lead to unavoidable data scattering (Walling 1977; 1983). For instance, the torrential rainfall brought by serial typhoons may have accumulated effects on raising soil water content, thereby reducing the threshold for triggering landslides (Hovius et al. 2000; Fuller et al. 2003). Episodic landslides generate extra sediment supplies from hill slopes or riverbanks upstream that 
consequently result in data scattering at downstream stations (Kao 1995). On the other hand, more diffusive data points at low flow rates are generally induced by gravel mining along the riverbed, channel modification, and bridge construction (Kao 1995), which are independent of rainfall or water discharge. Apparently, the long-term scattering sedimentation pattern is composed of distinct short-term patterns (Kao and Liu 2001, 2002; Syvitski et al. 2000). A more serious scattering distribution was reported for Oregon Coast Range streams (Beschta 1978) and rivers in Costa Rica (Jansson 1996) due to road construction and dynamic meteorological conditions, respectively.

\subsection{Sediment Sampling Tendency}

Understandably the WRA takes more sediment samples during the typhoon seasons, when the major outflow of water and sediment occur. A probability analysis was conducted to
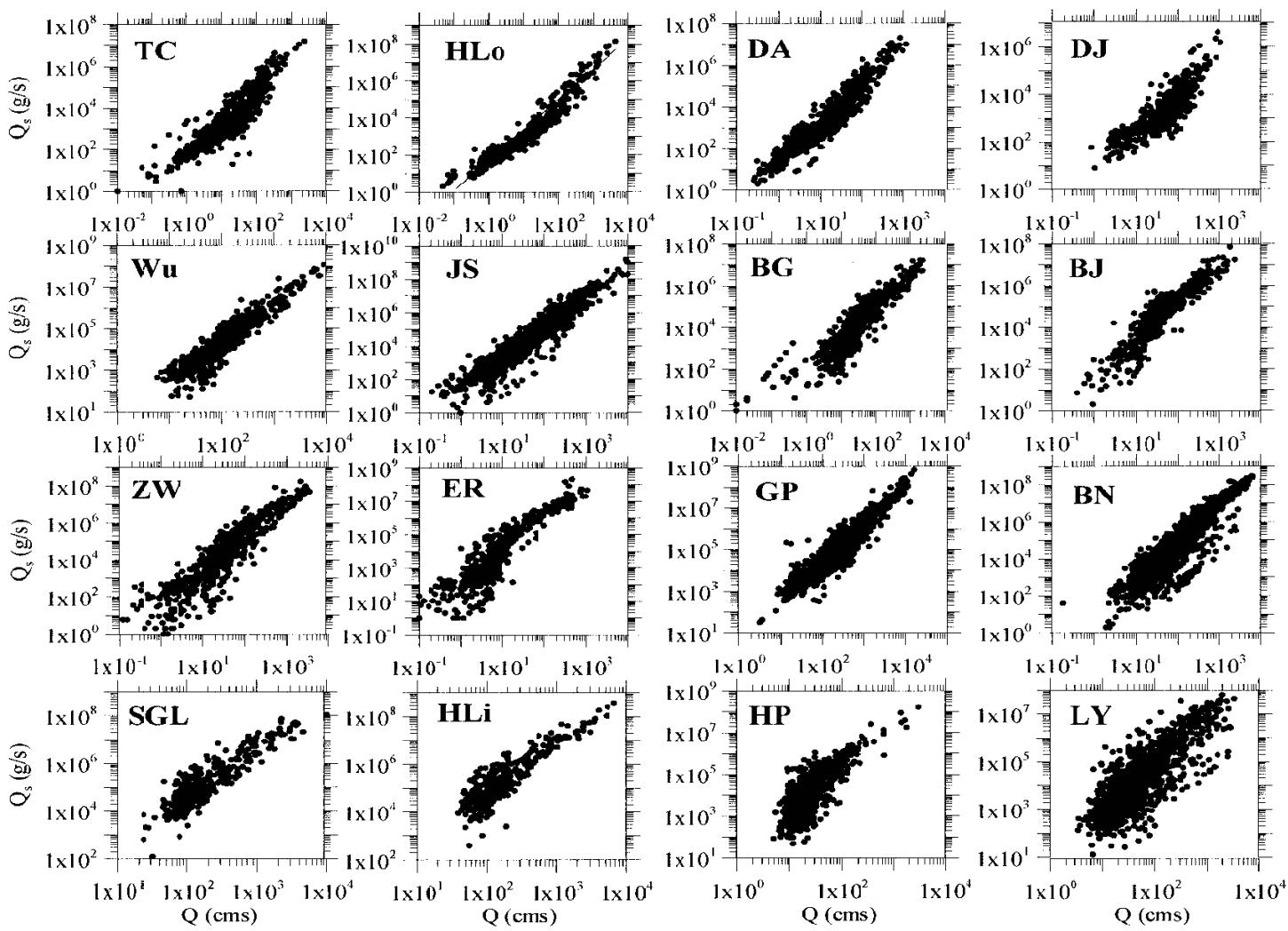

Fig. 3. Scatter plots for sediment load (Y-axis) against water discharge rate (Xaxis). For the Hou-Long River, a single rating curve is made as an example by using the pooled data set (see text). 
examine the tendency of sediment sampling of the historical record throughout the entire range of water discharge. For comparison, the probability density for the corresponding water discharge during sediment sampling was plotted with that of the recorded daily water discharge rate (Fig. 4). The probability distributions of sediment sampling for most rivers are skewed toward high flows. This sampling scheme benefits some methods yet has disadvantages on other methods (see below).

\section{METHODS OVERVIEW}

Calculating annual sediment load of a river can be quite straightforward if discharge and sediment concentration are measured at closely spaced intervals, particularly during floods. In most cases, however, a continuous record of sediment concentration is not available, and indirect methods must be utilized, often using a sediment rating-curve. Below we discuss various methods used to calculate sediment load.
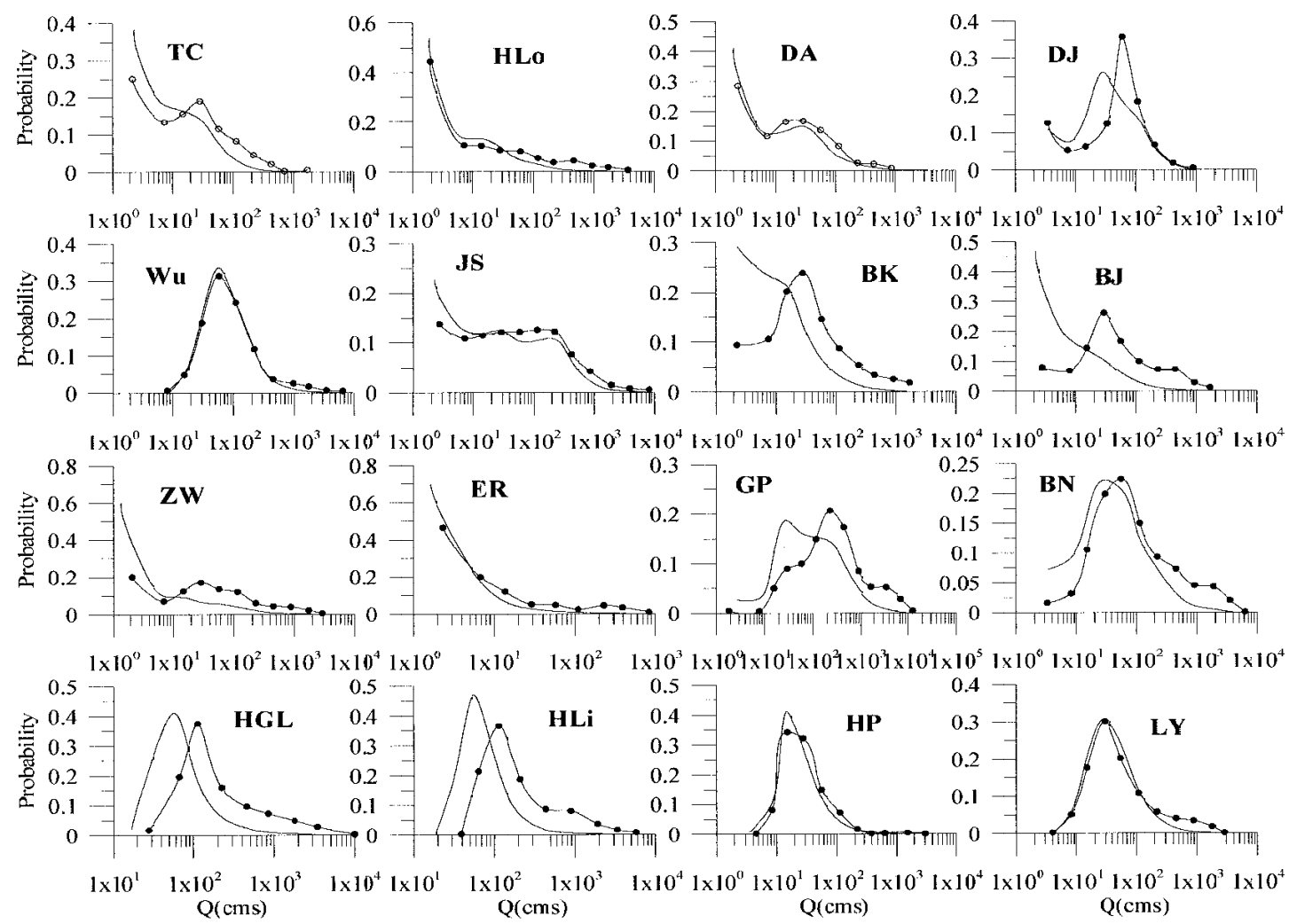

Fig. 4. Probability distributions of daily water discharge rate (curve) and corresponding water discharge rate during sediment sampling (curve with dots). 


\subsection{Rating Curve}

The rating curve is a widely adopted method for estimating sediment concentration and load (Campbell and Bauder 1940; Walling 1977; Ferguson 1987; Crawford 1991; Jansson 1996; Gordova and Gonzalez 1997; Inman and Jenkins 1999; Syvitski and Morehead 1999; Syvitski et al. 2000; Asselman 2000; Horowitz 2003). Since sediment concentration and load often vary over several orders of magnitude, the rating curve is generally established by a power function relating available sediment load $\left(Q_{s}\right)$ to water discharge $(Q)$ :

$$
Q_{s}=C_{s} \cdot Q \cdot 1000=a Q^{b},
$$

where $Q_{s}\left(\mathrm{~g} \mathrm{~s}^{-1}\right)$ is sediment load, which is the product of observed suspended-load concentration, $C_{s}\left(g l^{-1}\right)$, and a corresponding $Q\left(\mathrm{~m}^{3} \mathrm{~s}^{-1}\right)$, and a and $\mathrm{b}$ are the sediment rating coefficient and exponent, respectively.

The rating curve is assumed to represent a continuous relationship over the entire range of water discharge. Thus one can apply a full-range of $Q$ records to interpolate (sometimes extrapolate) the daily loads (or hourly loads) over a given time period.

River conditions in Taiwan, however, are so dynamic that the rating relationship at a given station may remain stationary for only a short period of time (Kao and Liu 2001; 2002). The major advantage of the rating curve method is that we can stratify long-term historical data and construct more than one rating curve for specific time intervals (Kao and Liu 2001) and for a specific range of water discharges (Gordova and Gonzalez 1997). Fortunately, WRA's frequent sampling at high flows benefits rating curve construction. If the time interval is properly stratified (i.e., sufficient sediment observations for regression and acceptable extrapolation), we can obtain an optimal rating curve based on short-term data, thereby allowing us to calculate sediment transport over any time span. In fact, constructing the short-term rating curve is also important in characterizing small mountainous rivers since previous studies have indicated temporal and spatial variations of rating relationships might serve as proxies for changes in watershed conditions, climate, and sediment sources (Syvitski et al. 2000; Krishnaswamy et al. 2000, 2001; Dadson et al. 2004b).

\subsection{Event-based Rating Curves}

For highly variable rivers in Taiwan, event-based rating curves should be best for estimating sediment loads (Walling 1977, 1983; Moliere et al. 2004). Milliman and Kao (2005) used such curves to estimate sediment concentrations and loads of eight Taiwan's rivers during Typhoon Herb in 1996. A close inspection of most reported $C_{s}$ values, in fact, shows that the $C_{s}-Q$ data for many Taiwan rivers can be divided into three subgroups: pre-event, event (in some years not one but two typhoons), and post-event. Because pre-event $C_{s}$ and $Q$ values are generally small, calculated $Q_{s}$ values are nearly always very small, and in most cases can be ignored in the calculation of annual sediment loads. Event $C_{s}$ and $Q$ values (particularly typhoon-generated), on the other hand, dominate most rivers' annual sediment loads, although in some cases post-event $C_{s}$ and $Q$ can be sufficiently great to affect a significant part of the 
annual sediment load. Calculated and observed $C_{s}$ values during Typhoon Herb show very close agreement, thus confirming the applicability of the event-based rating curve (Milliman and Kao 2005).

Unfortunately, developing event-based rating curves is laborious since it requires each year to be analyzed individually. Moreover, for most years and for most rivers, we do not have sufficient historical data to construct proper event-based rating curves.

\subsection{Flow-duration Rating Curves (FDRC)}

In this method, the average quantity of suspended sediment transport in a river over a given period of time (Miller 1951; Crawford 1991) is expressed as:

$$
L m=\sum_{\min Q}^{\max Q} f(Q) p(Q)
$$

where $L m$ is the mean load and the sediment rating curve is represented by a function of $Q$, $f(Q)$. Along with the probability density of $Q, p(Q)$, which is derived from the flow-duration data, one can calculate the mean sediment load. The representative $p(Q)$ for a given station can be derived only when the water discharge record is sufficiently long.

In this method, only one single rating curve is constructed from the cumulative data set, which basically assumes stationary river conditions throughout the record period (Horowitz 2003). Such an assumption conceptually eliminates other controlling factors that might be equally important in driving the inter-annual variability of sediment loads (Kao and Liu 2001, 2002; Dadson et al. 2004), leaving water discharge as the only control governing the sediment load. This is clearly not the case in the highly responsive and frequently perturbed Taiwan watersheds.

The long-term flow-duration curve based on a pooled database smoothes out extremely high-flow events, which have $<1 \%$ occurrence but $>80 \%$ contribution to sediment discharge. This method also precludes estimating short-term fluxes (Kao and Liu 2001) and causes large deviations in prediction, particularly at high flows. Looking at Fig. 3, it is clear that if we apply a single rating curve onto the pooled dataset with an upward bent pattern (e.g., HLo, as shown in Fig. 3), we will significantly under-predict $Q_{s}$ during high-flow events. Meanwhile, we can hardly reduce estimation errors based on a pooled diffusive dataset.

\subsection{Monthly Weighted Average (MWA)}

The monthly weighted average method (MWA) was proposed by Dadson et al. (2003). They suggested most of Taiwan's rivers are in supply-limited conditions (Hovius et al. 2000), which prevents the usage of a rating curve for sediment-load estimation. The MWA method evolves from the direct time-average method, which averages all observations directly. Since the direct time average uses only measured data, this method relies on the fewest assumptions. One important assumption is that sediment sampling is at a fixed time interval, which means no particular range of conditions is favored in the selection of sampling times. When high flow 
(or low flow) periods are preferentially chosen for measurements, the direct time-average method will overestimate (or underestimate) sediment loads. To reduce the bias induced by the unevenly distributed sampling frequency, Dadson et al. (2003) proposed the MWA method:

$$
Q_{s, \text { Mon }}=\frac{1}{12} \sum_{j=1}^{12}\left(\frac{1}{m_{i}} \sum_{j=1}^{m_{i}} Q_{s_{i j}}\right)
$$

where $Q_{s_{i j}}$ is the $j$ th observation of sediment discharge in the ith month, in which there are $m_{i}$ observations. This average of the monthly averages was believed to efficiently eliminate bias associated with increased sampling frequency in some months (Dadson 2004), because the average equal weight is given to each monthly average rather than to each observation. However, as mentioned above, the WRA historically has increased sample collection during high-flow conditions. Whether such a sampling strategy might bias the MWA method toward overestimation requires evaluation. Meanwhile, this method can only be applied when sampling has been made over a sufficiently long period. Similar to the FDRC, this method inevitably precludes the delineation of any short-term variability in sediment flux.

\subsection{Power Equation, Estimation Residual and Bias-correction}

To obtain a power equation, whether it should be developed iteratively using a leastsquare method and a logarithmic linear regression, is controversial. Iteratively developed power regression has been found to give equations that calculate the load reasonably accurately if it converges to a solution (Jansson 1985; Crawford 1991; Jansson 1996; Asselman 2000). However, Crawford (1991) argued that the predictive capability of the power regression model is low due to the heavy weighting of high values at high discharges at the same time that concentration variations are greatest at high discharges. Also, iteratively developed regression needs more computer memory and computer time than linear regressions on log-transformed data (Jansson 1996). Therefore, most studies use log-log linear regression to obtain the power equation.

However, power equations obtained by logarithmic linear regression following a logtransformation are well known to have predictions biased downwards (i.e., they underestimate; Thomas 1985; Koch and Smillie 1986; Ferguson 1986, 1987; Cohn et al. 1989; Cohn 1995). In the linear regression model, residuals (defined as the differences between each observed value and its prediction) should be normally distributed and the expected value of the residual distribution is zero. However, when the linear-modeled predictions are back-transformed to original units, the residuals are no longer normally distributed and the expected value therefore is generally greater than 0 (i.e., underestimation).

To overcome the back log-transformation bias, several statistical techniques have been developed such as the maximum likelihood estimate (Ferguson 1986), minimum variance unbiased estimate (Thomas 1985; Cohn et al. 1989), non-parametric smearing estimator (Duan 1983), and similar methods by imposing the correction factor on estimations (Miller 1984; Jansson 1996). Overall these statistical techniques are devised to compensate for underestimation; that is, they all 
move predictions upward. The magnitude of correction can be derived from the residuals under statistical assumption of a log-log linear regression model, and work adequately if the sum of predictions is truly underestimated; otherwise corrections will worsen the already overestimation (Ferguson 1987; e.g., HLo, as shown in Fig. 3). The application of bias-corrections in real cases is therefore limited since the corrections may result in further overestimations. To accommodate various scatter patterns in the $\log Q_{s}-\log Q$ plots when we apply $\log$-log linear regression, we develop a new bias-correction factor.

\subsubsection{A new Bias-correction}

In contrast to the previous bias-corrections, which are based on residuals in log-transformed units and back-transformed again before using them (thus allowing only positive corrections), we define residuals in non-log transformed units (Eq. 4) in our new bias-factor calculation. Firstly the residual error in rating curve prediction is calculated:

$$
Q_{s i}=a Q_{i}^{b}+\varepsilon_{i},
$$

where $Q_{s i}, Q_{i}$ and $\varepsilon_{i}$ are observed sediment load, corresponding water discharge, and the residual error between observation and prediction, respectively, for the $i$ th sediment observation. The bias-correction factor, $\beta$, is defined as the sum of residuals divided by the sum of total predictions:

$$
\beta=\frac{\sum_{i=1}^{N}\left(\varepsilon_{i}\right)}{\sum_{i=1}^{N} a Q_{i}^{b}}, \quad i=1 \sim N,
$$

where $N$ is the number of observations in the dataset. The factor $\beta$ can be positive or negative; therefore, bias-correction can be made in both directions of the rating relationship mentioned above. This is a significant improvement. A corrected relationship between $\hat{Q}_{s}$ and $Q$ is then given by:

$$
\hat{Q}_{s}=(1+\beta) \cdot a Q^{b} .
$$

Since $Q_{s}$ expands over 6 orders of magnitude, much larger residual errors always appear at high-flow predictions, which have heavier weighting in determining $\beta$ value (as in Eq. 5) while being compared to those residuals for low-flow predictions. Accordingly, this $\beta$ factor can efficiently modify the rating curve toward the largest dependent variable $\left(Q_{s}\right)$, which means the largest sediment load in a respective dataset could be predicted better. Meanwhile, positive and negative residuals in the corrected equation (Eq. 6) will be balanced out and the sum of total predictions will approximate the sum of total observations. Estimation error is thus sig- 
nificantly reduced. In a subsequent discussion we evaluate the predictive capability of our bias-corrected log-log linear regression by comparing with observed data, predictions derived by using iteratively developed power regression and predictions derived from event-based rating curves.

\section{DEVELOPING SEASON BASED OPTIMAL RATING CURVES}

To develop season-based rating curves, we stratified the WRA's dataset into two categories: typhoon (June to October) and non-typhoon (November to the following May) periods (as shown in Fig. 2). As with the event-based curve, this helps avoid interference from diffusive data points observed during low-flow seasons (Fig. 3) and to predict more accurately daily loads at high-flows. This method shares with others the concept of using the flow rate-based "truncated rating curve" to predict better the sediment loads at high-flow rates (e.g., Jansson 1996; Gordova and Gonzalez 1997; Meybeck et al. 2003), but also recognizes the very much greater $Q$ and $C_{s}$ values observed during typhoon events.

In some years we have insufficient data, particularly to define typhoon-related sediment concentrations. We therefore established three criteria to determine the shortest but optimal time interval for rating curve construction: 1) A minimum of five data points for each rating curve; 2) A $Q$-range check to avoid excessive extrapolation error and to ensure a proper rating curve for transforming the entire range of stream-flow. We qualify each stratified data set as adequate for rating curve construction if logarithm of maximum daily $Q$ is less than 1.2 times the logarithm of maximum $Q$ during sediment sampling. 3) The coefficient of determination $\left(R^{2}\right)$ must be greater than 0.75 , ensuring that the log-log linear regression is statistically meaningful. If seasonal datasets in any year fail to satisfy all of the three criteria, the yearly rating curve is used instead for load estimation for the respective season. Similarly, if yearly datasets cannot match our criteria, a three-year rating curve, which includes sediment samples in the previous and following year, is applied to estimate sediment transport for the respective season. The bias-corrected optimal-time-interval rating curve is subsequently used to convert daily water discharge rates into the daily sediment loads. During events, hourly data are applied (Kao and Liu 2001; Milliman and Kao 2005). By summing up these derived daily (or hourly) sediment loads, we derive the annual sediment load.

The $R^{2}$ for the optimal rating curve based on stratified data set is shown in Fig. 5. For all but the HP River, $R^{2}$ values are high except for some short periods. Consistently high $R^{2}$ values indicate good correlation of rating relationships for most time frames. The HP River, in fact, is the worst case, having many $R^{2}$ values $<0.75$. Those years with low $R^{2}$ values accompany with larger residual errors in the annual loads (see below). Therefore, final positive and negative residuals in the regression are representative of under-estimation and over-estimation errors, respectively, for the specific time period.

The temporal variations of rating slopes for 16 rivers show wide ranges from 1 to over 3 , indicating varying watershed conditions throughout the recorded period (Fig. 6). Though the rating slopes are highly variable, our method gives high $R^{2}$ values, indicating that the program is capable of determining an optimal time interval for rating curve construction. The dynamic 

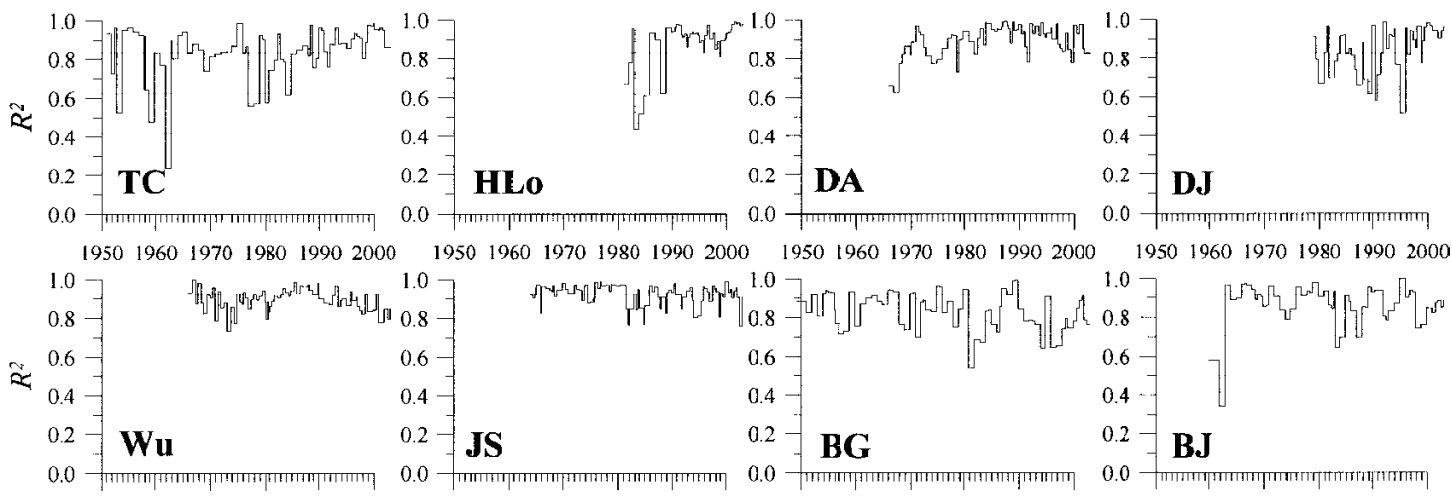

195019601970198019902000
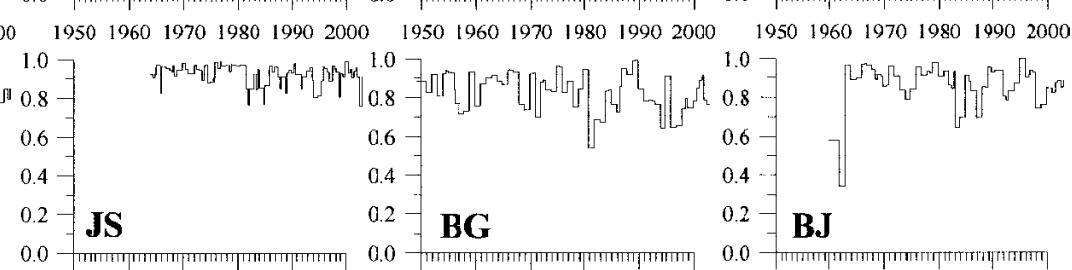

$195019601970198019902000 \quad 195019601970198019902000 \quad 195019601970198019902000 \quad 195019601970198019902000$

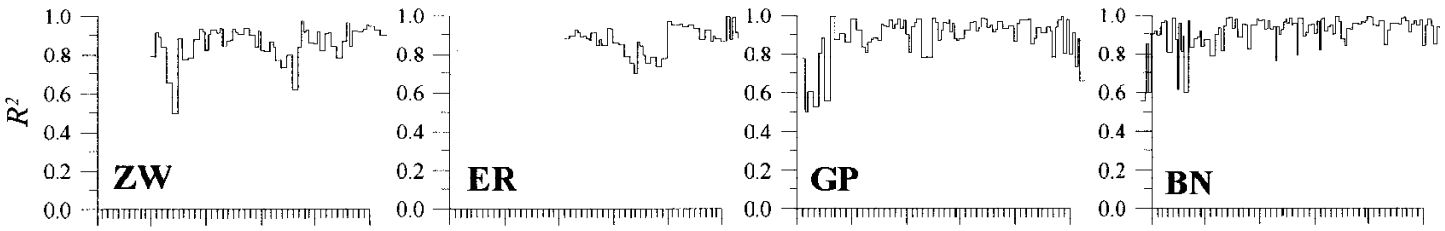

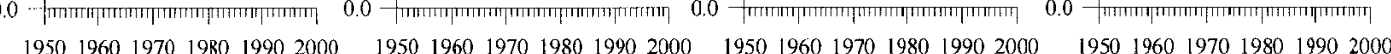
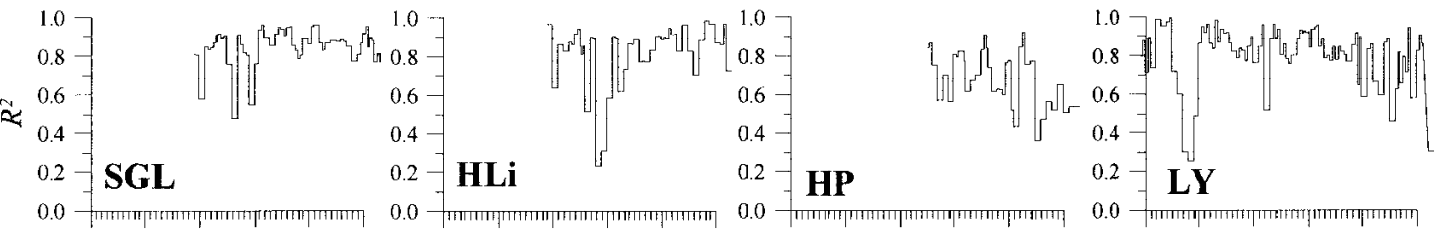

$195019601970198019902000 \quad 195019601970198019902000 \quad 195019601970198019902000 \quad 195019601970198019902000$

Fig. 5. Temporal variations of $R^{2}$ values derived from optimal rating curves.

range of rating slopes is attributable to various degrees of in-basin disturbances since a given $Q$ over different time intervals can generate 2 orders of magnitude difference in $Q_{s}$. Accordingly, water discharge turns out not to be the only control of sediment discharge. Such fluctuating relationships recorded at the most downstream stations further illustrate that mountainous watersheds are very responsive to upstream disturbances. Therefore, our method of data stratification raises the potential to uncover the magnitude of in-basin disturbances, and to separate hydrologic from anthropogenic forcing.

Optimization of rating curve method also is validated by comparing the predicted against observed values on scatter plots (Fig. 7). For all rivers, scatter plots reveal very good agreement since most data points fall tightly along a $1: 1$ log-linear line. Those high-loading observations are well predicted regardless of various sedimentation patterns as mentioned earlier. Even by visual justification, we can see the positive residuals are balanced out by negative residuals. For the HP River, which has many low $R^{2}$ values, observed values at high-flow rates are not well predicted, yet still are distributed on both sides of the $1: 1$ line. Even for the DJ River, where three hydropower stations along the main channel upstream may artificially alter rating relationships, we still predict well. This validation indicates that our bias-correc- 

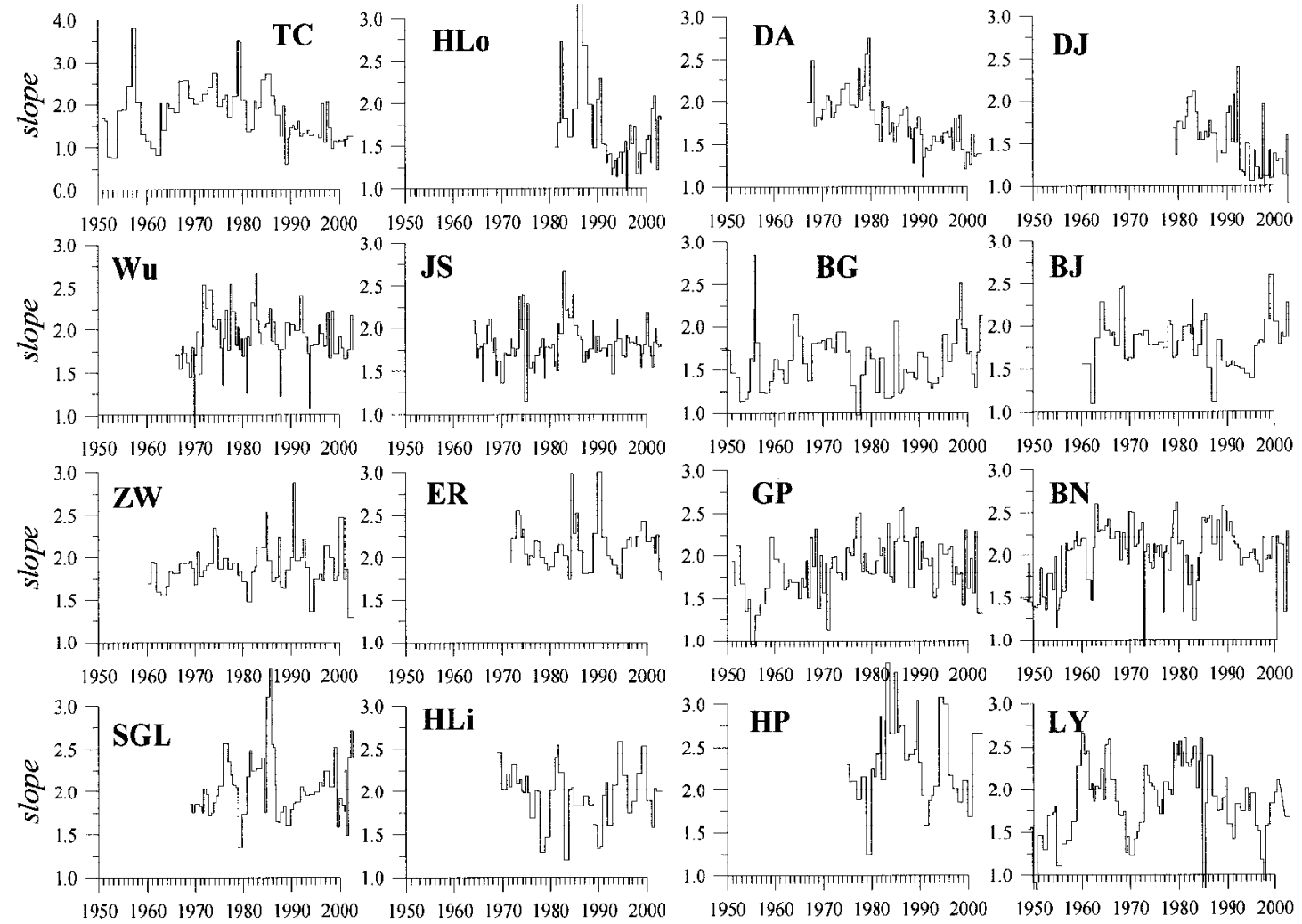

Fig. 6. Temporal variations of rating slope values derived from optimal rating curves.

tion coupled with an optimal time interval rating curve facilitates a full range of sediment load simulation.

The Jhou-Shuei River is taken as an example showing the temporal variation of predicted and observed values (Fig. 8). The simulated loads show a dynamic range fitting well with the observed values even though the fluctuation is over 7 orders of magnitude. In this example, we can see the sum of the positive and negative residuals may serve as envelope values (error bars) representing, respectively, largest under- and over-estimations. Two contrasting examples were shown in Fig. 9. The Jhou-Shuei River (Fig. 9a), which has most $R^{2}$ values higher than 0.75 , shows narrow residual error bars for most years even though in recent years the JhouShuei River has experienced the Super Typhoon Herb in 1996 (Milliman and Kao 2005), the Chi-Chi Earthquake ( $\left.M_{w}=7.6\right)$ in 1999 (Dadson et al. 2003, 2004), and Typhoon Toraji in 2001. By contrast, the HP River (Fig. 9b) is the worst case, having larger error bars as reflected by lower $R^{2}$ values. These error bars are useful in annual load presentation, which can describe statistical differences in the inter-annual variability. Thus we suggest residual errors in rating-curve prediction should be attached as we reported sediment loads. 

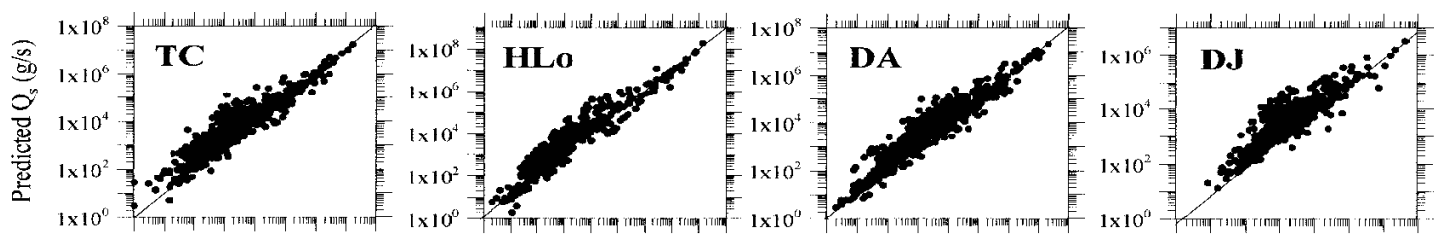
$1 \times 10^{\circ} 1 \times 10^{2} 1 \times 10^{4} 1 \times 10^{6} 1 \times 10^{8} \quad 1 \times 10^{6} 1 \times 10^{2} 1 \times 10^{11} 1 \times 10^{6} 1 \times 10^{8}$ $1 \times 10^{10} 1 \times 10^{2} 1 \times 10^{4} 1 \times 10^{6} 1 \times 10^{\circ}$ $1 \times 10^{\circ} \quad 1 \times 10^{2} \quad 1 \times 10^{4} \quad 1 \times 10^{\circ}$
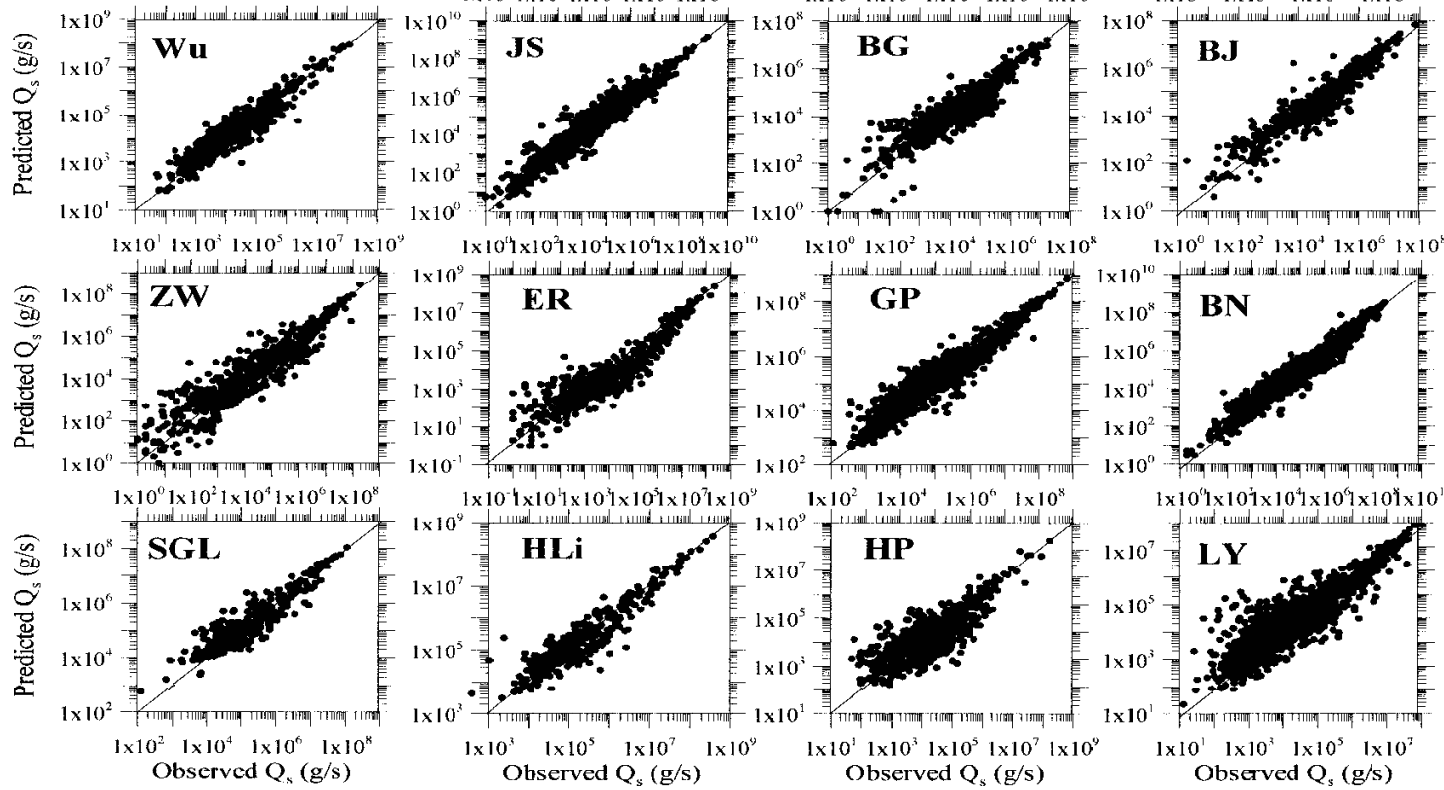

Fig. 7. Scatter plots for predicted load and observed load. $1: 1$ line is also shown.

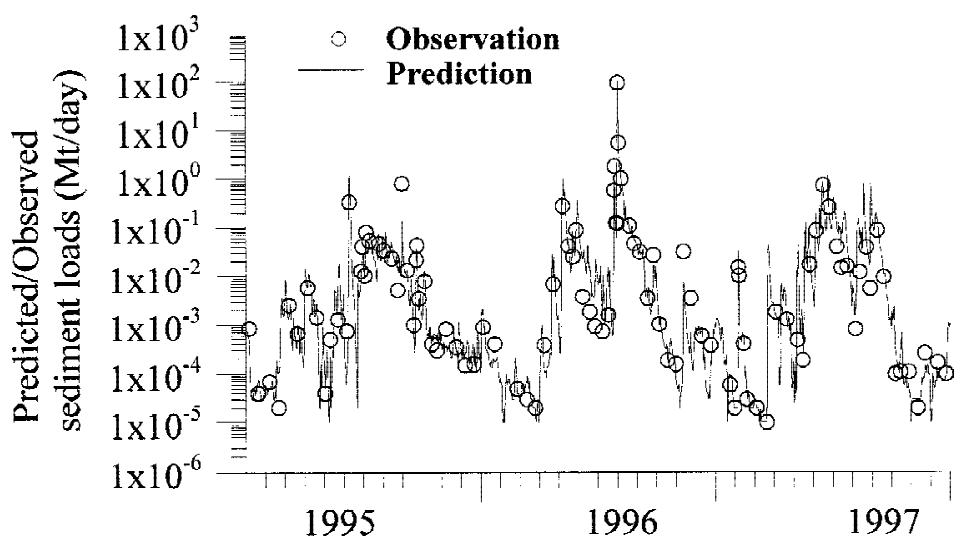

Fig. 8. Temporal variations of observed and predicted sediment loads for the Jhuo-Shuei River, 1995-97. 


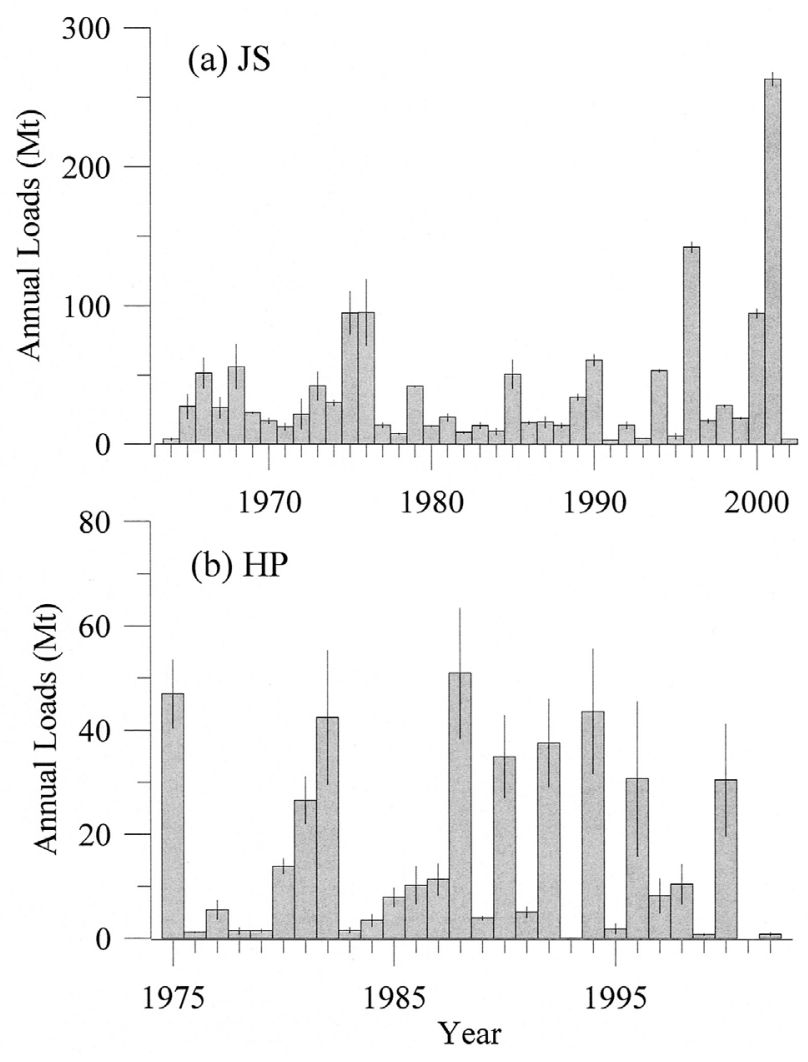

Fig. 9. Temporal variations of annual total sediment load for the Jhuo-Shuei River (a) and for the Ho-Ping River (b). Error bars are also shown.

\section{NON-LINEAR SEDIMENT RESPONSE TO WATER DISCHARGE}

As mentioned earlier, the application of hourly water discharge is particularly critical in simulating the sediment hydrograph during episodic events. Using two events in the JS and $\mathrm{BN}$ for example, the differences in calculations between using hourly and daily water discharges are significant (Fig. 10) since calculated sediment loads represent a power function of discharge, differences for these two parameters are far greater. Moreover, hourly-derived sediment concentrations (Figs. 10b, e) allow us to define the timing and fractional contribution of hyperpycnal flow, whereas concentrations from daily water discharge generally miss such events. The cumulative sediment loads (Figs. 10c, f) indicate at the beginning a higher export can be obtained by using the daily flow data, while during the flood peak period the daily flow can only generate lower exports, resulting in significant offset relative to that by using hourly flow data. The integrated discrepancies over the event period are 31 and 50\%, respectively, for the events in the JS and BN. The offset is obviously attributed to the non-linear sediment response to the water discharge rate. 

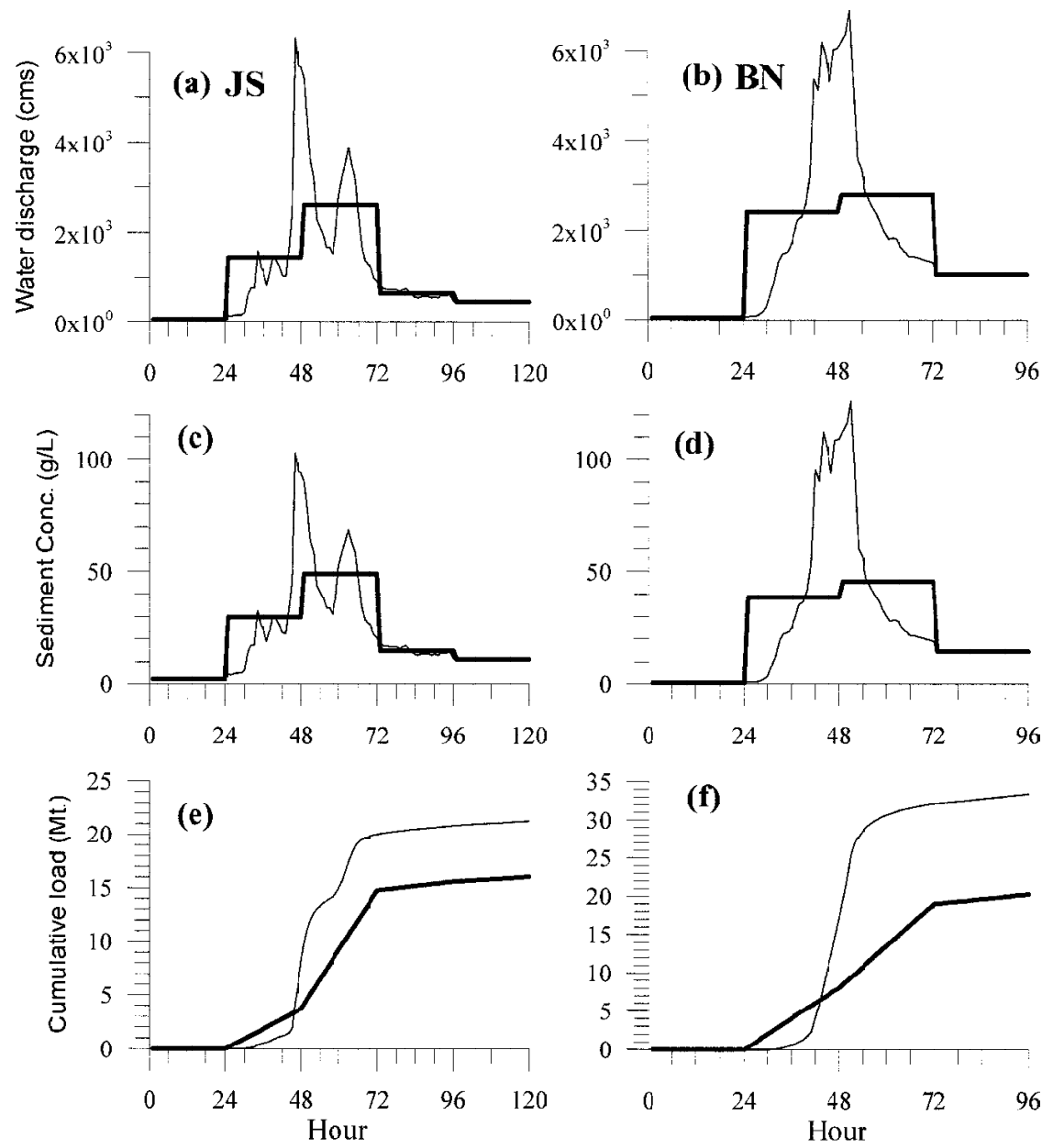

Fig. 10. Two hydrograph examples from the Jhuo-Shuei (a, c, e; Spet. 16 - 20 2001, Typhoon Nari) and the Bei-Nan (b, d, f; Oct. 30 - Nov. 2, 2000, Typhoon Xangsane). The temporal variation of hourly (dashed curve) and daily (bold line) water discharge (a, b). The sediment concentrations (c, d) and cumulative loads (e, f) derived by using hourly and daily water discharge during the event periods.

\section{PREDICTIVE CAPABILITY AMONG METHODS}

We used 49 major events from four rivers (JS, $n=12$; BN, $n=33$; HLi, $n=3$; GP, $n=1$ ) to compare sediment loads calculated from seasonal- and event-based rating curves. The resulting comparison (Fig. 11) shows a close correlation along a $1: 1$ line.

We take two major flood events, Typhoon Herb in 1996 and Typhoon Toraji in 2001, in the JS River (Fig. 12), to examine event-based predictive capabilities between the three meth- 
ods (event-based rating curve, seasonal rating curve and the iteratively developed power regression). The two event-based rating curves and equations were presented in Milliman and Kao (2005). During the 72 hours invasion of Typhoon Herb (Fig. 12a) all three methods fit closely with observations. But the iteratively developed power equation shows lower predicted concentrations at higher flows and higher prediction at lower flows when compared to the other two methods. In the case of Typhoon Toraji (Fig. 12b), all three methods fit observations well, but lower concentrations are obtained at higher flows by using an event-based curve.

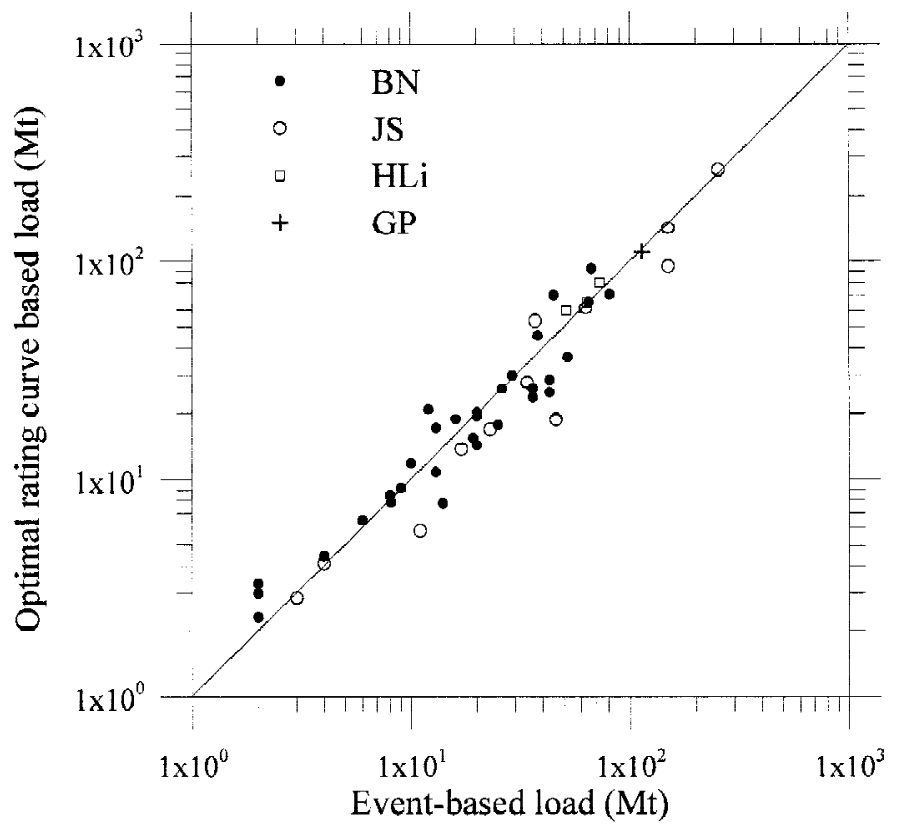

Fig. 11. Scatter plot for annual loads derived from event-based and optimal rating curves. 1 : 1 line is shown. BN: Bei-Nan; JS: Jhuo-Shuei; HLi: HuaLien; GP: Gao-Ping.

It is hard to validate those out-of-range predictions without measurements at peak flows. However, the flood peak lasted only a few hours and the largest difference in concentrations among three simulations is $\sim 20 \%$, which is better than what one might expect. The 72 -hour integrated sediment loads derived from the optimal rating curve, event-based rating curve, and iteratively developed power equation are 123, 123 and $115 \mathrm{Mt}$, respectively, for Typhoon Herb; and 194, 175 and 193 Mt, respectively, for Typhoon Toraji. The main reason for such a close prediction in integrated total is because high flows give better values than low flows do. Thus compensation is achieved when we integrate hourly loads over the entire event period. Results indicate the predictive capability of the bias-corrected optimal rating curve not only fulfills the annual level but also reaches the event-level prediction, which helps decipher the hyperpycnal flow events from historical data (Milliman and Kao 2005; Dadson et al. 2005). 

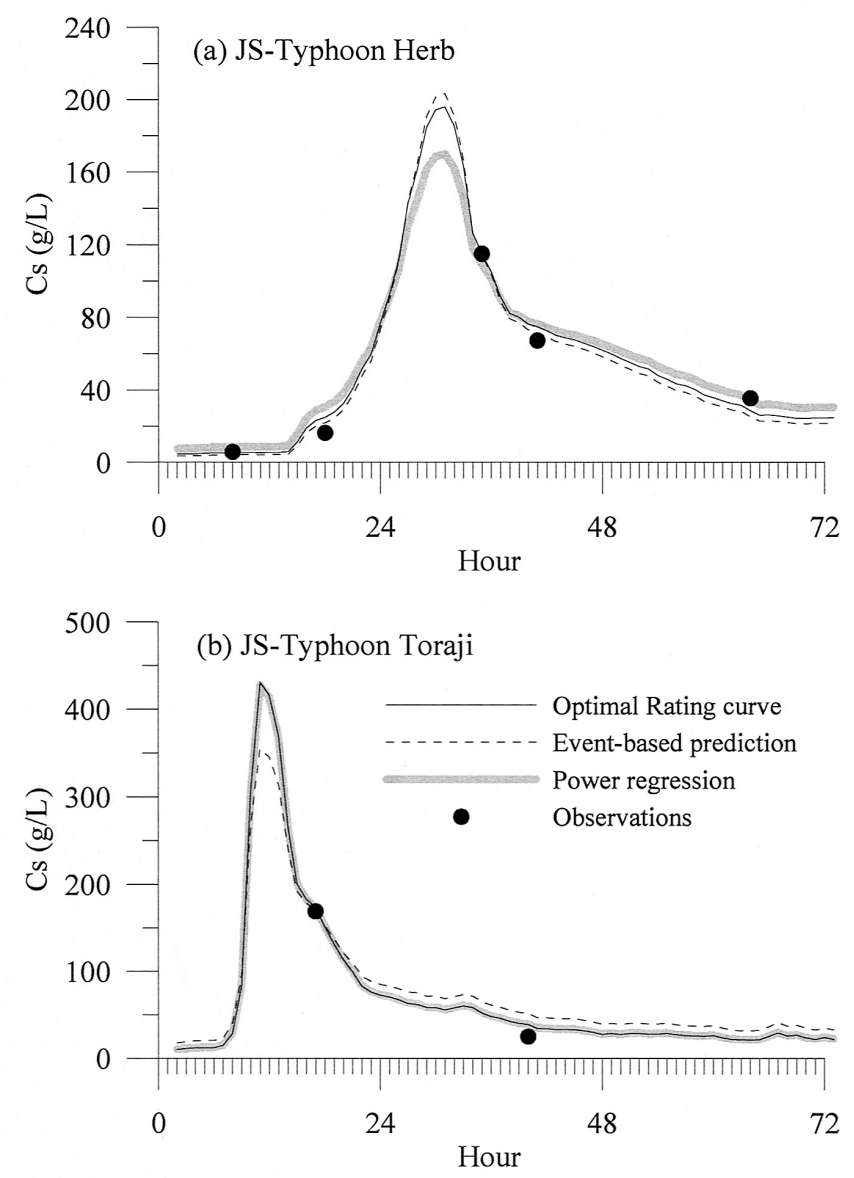

Fig. 12. The temporal variations of predictions derived from the optimal rating curve (thin black curve), event-based curve (dashed curve), power regression (gray bold curve) and observations (filled circles) during (a) Typhoon Herb and (b) Typhoon Toraji.

\section{COMPARISON WITH REPORTED LONG-TERM MEANS}

To obtain the long-term mean annual sediment loads, we can use the MWA, the FDRC, or take an average of annual loads calculated by our optimal rating curve method for three of Taiwan's rivers (Table 2). Our calculated mean annual sediment load $\left(16 \mathrm{Mt} \mathrm{yr}^{-1}\right)$ for the HoPing (HP) River agrees closely with that calculated by Dadson et al. (2003; $15 \mathrm{Mt} \mathrm{yr}^{-1}$ ). Our calculated mean annual sediment load for the Jhou-Shuei between 1964 and 2002 (38 $\mathrm{Mt} \mathrm{yr}^{-1}$ ), on the other hand, is considerably smaller than calculated using the MWA (110 $\mathrm{Mt} \mathrm{yr}^{-1}$ ) or reported by the WRA (64 Mt yr ${ }^{-1}$ ) (Table 2). The mean annual load between 1986 and 2002 
calculated by Dadson et al. (54 $\mathrm{Mt} \mathrm{yr}^{-1}$ ) is about 50\% higher than the $35 \mathrm{Mt} \mathrm{yr}^{-1}$ (not shown in Table 2) we have calculated for the same period. Most possible cause is that in such highly fluctuating rivers the MWA method cannot properly remove the bias induced by higher sampling frequency in flood seasons.

Our calculated load for the Bei-Nan (BN) River $\left(18 \mathrm{Mt} \mathrm{yr}^{-1}\right)$ is about $30 \%$ lower than the $25 \mathrm{Mt} \mathrm{yr}^{-1}$ reported by the WRA, but nearly 5 times lower than the $88 \mathrm{Mt} \mathrm{yr}^{-1}$ calculated by Dadson et al. (2003). The latter value, which is equivalent to an average of $\sim 30 \mathrm{~g} \mathrm{l}^{-1}$ for each suspended-sediment sampling in the Bei-Nan since 1948, is likely to be overestimated, considering that of the 1731 samples taken in the river (Table 1), only 31 have yielded higher sediment concentrations.

Table 2. Long-term mean sediment loads (mean \pm residual error; unit in Mt) for 3 major rivers. Number in parenthesis represents the mean value difference between the respective methods and the optimal rating curve method.

\begin{tabular}{ccccc}
\hline River & This study $^{a}$ & MWA $^{b}$ & FDRC $^{c}$ & MWAl $^{d}$ \\
\hline Jhuo-Shuei (JS) & $38 \pm 6$ & $110(72)$ & $64(26)$ & 54 \\
Bei-Nan (BN) & $18 \pm 3$ & $94(76)$ & $25(7)$ & 88 \\
Ho-Ping (HP) & $16 \pm 4$ & $14(-2)$ & -- & 15 \\
\hline
\end{tabular}

$a$ : The record period for each station shown in Table 1.

$b$ : MWA applied to the same dataset in this study.

$c$ : Data taken from the WRA Hydrological Yearbooks.

$d$ : Values taken from Dadson et al. (2003), who used different record lengths.

\section{CONCLUSIONS}

To obtain the long-term mean sediment load for the highly variable Taiwan rivers, we suggest deriving a sediment-rating curve based on stratifying the long-term database into seasonal groupings on an annual basis, thus allowing for rapid changes in watershed conditions. A bias-corrected optimal rating curve gives us good predictions and significantly reduces estimation errors. Results derived from bias-corrected optimal rating curve, event-based rating curve, and non-corrected iteratively developed power regression methods agree well among each other, indicating a high predictive capability of our seasonal-based rating curve. The higher frequency of sediment observations during high-flow seasons benefits the rating-curve construction, but the recently proposed MWA method may over estimate mean sediment load. The programmable optimal rating-curve method not only saves time in dealing with the large historical database but also allows us to reconstruct the history of daily (even hourly) sediment discharge, thereby permitting us to quantify watershed responses to human disturbances (e.g., dam and road construction, agriculture) as well as natural events. 
Acknowledgements This study was supported by grant (NSC 93-2116-M-001-019) from the National Science Council of Taiwan (to SJK) and various grants from the U.S. Office of Naval Research and National Science Foundation (to JDM). We thank the Water Resources Agency, Taiwan for data provision. Reviews by J.P.M. Syvitski and two anonymous reviewers of an earlier draft are gratefully acknowledged.

\section{REFERENCES}

Asselman, N. E. M., 2000: Fitting and interpretation of sediment rating curves. J. Hydrol., 234, 228-248.

Beschta, R. L., 1978: Long-term pattern of sediment production following road construction and logging in the Oregon Coast Range. Water Resour. Res., 14, 1011-1016.

Campbell, F. B., and H. A. Bauder, 1940: A rating-curve method for determining silt-discharge of streams. EOS, 21, 603-607.

Cohn, T. A., L. L. DeLong, E. J. Gilroy, R. M. Hirsch, and D. K. Well, 1989.:Estimating constituent loads. Water Resour. Res., 25, 937-942.

Cohn, T. A., 1995: Recent advances in statistical methods for the estimation of sediment and nutrient transport in rivers. Rev. Geophys., Supplement, 1117-1123.

Crawford, C. G., 1991: Estimation of suspended-sediment rating curves and mean suspendedsediment loads. J. Hydrol., 129, 331-348.

Dadson, S. J., N. Hovius, H. Chen, W. B. Dade, M. L. Hsieh, S. D. Willett, J. C. Hu, M. J. Horng, M. C. Chen, C. P. Stark, D. Lague, and J. C. Lin, 2003: Links between erosion, runoff variability and seismicity in the Taiwan orogen. Nature, 426, 648-651.

Dadson, S. J., 2004: Erosion of an active mountain belt. Ph.D. Thesis, Dept. Earth Sci., Univ. Cambridge.

Dadson, S. J., N. Hovius, H. Chen, W. B. Dade, J. C. Lin, M. L. Hsu, C. W. Lin, M. J. Horng, T. Chen, J. D. Milliman, and C. Stark, 2004: Earthquake-triggered increase in sediment delivery from an active mountain belt. Geology, 32, 733-736.

Dadson, S. J., N. Hovius, S. Pegg, W. B. Dade, and M. J. Horng, 2005: Hyperpycnal river flows from an active mountain belt. Submitted to J. Geology.

Duan, N., 1983: Smearing estimate-a nonparametric retransformation method.J. Am. Stat. Assoc., 78, 605-610.

Farnsworth, K. L., and J. D. Milliman, 2003: Effects of climatic and anthropogenic change on small mountainous rivers: the Salinas River example. Glob. Planet. Change, 39, 53-64.

Ferguson, R. I., 1986: River loads underestimated by rating curves. Water Resour. Res., 22, 74-76.

Ferguson, R. I., 1987: Accuracy and precision of methods for estimating river loads. Earth Surf. Proc. Landf., 12, 95-104.

Fuller, W. C., S. D. Willett, N. Hovius, and R. L. Slingerland, 2003: Erosion rates for mountain basins: new determinations from suspended sediment records and a stochastic model of their temporal variation. J. Geol., 111, 71-87. 
Gordova, J. R., and M. Gonzalez, 1997: Sediment yield estimation in small watersheds based on streamflow and suspended sediment discharge measurements. Soil Technol., 11, 5765.

Horowitz, A. J., 2003: An evaluation of sediment rating curve for estimating suspended sediment concentration for subsequent flux calculations. Hydrol. Proc., 17, 3387-3409.

Hovius, N., C. P. Stark, H. T. Chu, and J. C. Lin, 2000: Supply and removal of sediment in a landslide-dominated mountain belt: Central Range, Taiwan.J. Geol., 108, 73-89.

Inman, D. L., and D. L. Jenkins, 1999: Climate change and the episodicity of sediment flux of small Californian rivers. J. Geol., 107, 251-270.

Jansson, M. B., 1985: A comparison of detransformed logarithmic regressions and power function regressions. Geogr. Ann., 67, 61-70.

Jansson, M. B., 1996: Estimating a sediment rating curve of the Reventazon river at Palomo using logged mean loads within discharge classes. J. Hydrol., 183, 1996.

Kao, S. J., 1995: The biogeochemistry of carbon on an island of high denudation rate: a case study of the Lanyang-Hsi watershed. PhD Thesis, Nat. Taiwan Univ., Taiwan. 262 pp. (in Chinese)

Kao, S. J., and K. K. Liu, 1996: Particulate organic carbon export from a subtropical mountainous river (Lanyang-Hsi) in Taiwan. Limnol. Oceanogr., 41, 1749-1757.

Kao, S. J., and K. K. Liu, 2000: Stable carbon and nitrogen isotope systematics in a humandisturbed watershed (Lanyang-Hsi) in Taiwan and the estimation of biogenic particulate organic carbon and nitrogen fluxes. Glob. Biogeochem. Cycles., 14, 189-198.

Kao, S. J., and K. K. Liu, 2001: Estimating the suspended sediment load by using the historical hydrometric record from the Lanyang-Hsi watershed.Terres. Atmos. Ocean. Sci. 12, 401-414.

Kao, S. J., and K. K. Liu, 2002: Exacerbation of erosion induced by human perturbation in a typical Oceania watershed: insight from 45 years of hydrological records from the Lanyang-Hsi River, northeastern Taiwan. Glob. Biogeochem. Cycles, 16, doi: 10.1029/ 2000 GB001334.

Kao, S. J, S. C. Chan, C. H. Kuo, and K. K. Liu, 2005: Transport-dominated sediment loading in Taiwanese rivers: A case study from the Ma-an Stream. J. Geol., 113, 217-225.

Koch, R. W., and G. M. Smillie, 1986: Bias in hydrologic prediction using log-transformed regression models. Water Resour. Res., 22, 717-723.

Krishnaswamy, J., M. Lavrine, D. D. Richter, and K. Korfmacher, 2000: Dynamic modeling of long-term sedimentation in the Yadkin River basin. Adv. Water Resour., 23, 881892.

Krishnaswamy, J., P. N. Halpin, and D. D. Richter, 2001: Dynamics of sediment discharge in relation to land-use and hydro-climatology in a humid tropical watershed in Costa Rica. J. Hydrol., 253, 91-109.

Li, Y. H., 1976: Denudation of Taiwan island since the Pliocene epoch.J. Geol., 4, 105-107.

Liu, J. T., J. S. Huang, R. T. Hsu, and J. M. Chyan, 2000. The coastal depositional system of a small mountainous river: a perspective from grain-size distributions. Mar. Geol., 165, 63-86. 
Meybeck, M., L. Laroche, H. H. Durr, and J. P. M. Syvitski, 2003: Global variability of daily total suspended solids and their fluxes in rivers. Glob. Planet. Change, 39, 65-93.

Miller, C. R., 1951: Analysis of flow-duration, sediment-rating curve method of computing sediment yield. U. S. Bureau of Reclamation, April.

Miller, D. M., 1984: Reducing transformation bias in curve fitting. Am. Stat., 38, 124-126.

Milliman, J. D., 1991: Flux and fate of fluvial sediment and water in coastal seas. In: Mantoura et al. (Eds.), Ocean Margin Processes in Global Change, John Wiley \& Sons. 69-89.

Milliman, J. D., K. L. Farnsworth, and C. S. Albertin, 1999: Flux and fate of fluvial sediments leaving large islands in the East Indies. J. Sea. Res., 41, 97-107.

Milliman, J. D., and R. H. Meade, 1983: World-wide delivery of river sediment to the oceans. J. Geol., 91, 1-21.

Milliman, J. D., and J. P. M. Syvitski, 1992: Geomorphic/tectonic control of sediment discharge to the ocean: the importance of small mountainous rivers. J. Geology, 100, 525544.

Milliman, J. D., and S. J. Kao, 2005: Hyperpycnal discharge of fluvial sediment to the ocean: impact of Super-typhoon Herb (1996) on Taiwanese Rivers. J. Geol., in press.

Moliere, D. R., K. G. Evans, M. J. Saynor, and W. D. Erskine, 2004: Estimation of suspended sediment loads in a seasonal stream in the wet-dry tropics, Northern Territory, Australia. Hydrol. Proc., 18, 531-544.

Syvitski J. P. M., and M. D. Morehead, 1999. Estimating river-sediment discharge to the ocean: application to the Eel margin, northern California.Mar. Geol., 154, 13-28.

Syvitski, J. P. M., M. D. Morehead, D. B. Bahr, and T. Mulder, 2000: Estimating fluvial sediment transport: the rating parameters. Water Resour. Res., 36, 2747-2760.

Thomas, R. B., 1985: Estimating total suspended sediment yield with probability sampling. Water Resour. Res., 21, 1381.

Walling, D. E., 1977: Assessing the accuracy of suspended sediment rating curves for a small basin. Water Resour. Res., 13, 531-538.

Walling, D. E., 1983: The sediment delivery problem. J. Hydrol., 65, 209-237. 